\section{Volatile Compounds of the Curry Plant}

\author{
Denys J. Charles and James E. Simon \\ Department of Horticulture, Purdue University, West Lafayette, IN 47907
}

Additional index words. essential oils, Helichrysum italicum, H. angustifolium, herbs, spices

Abstract. The curry plant [Helichrysum italicum (Roth) G. Don in Loudon ssp. italicum or H. angustifolium (Lam.) DC (Asteraceae)], a popular ornamental herb with a curry-like aroma, was chemically evaluated to identify the essential oil constituents responsible for its aroma. Leaves and flowers from greenhouse-grown plants were harvested at full bloom. Essential oils were extracted from the dried leaves via hydrodistillation and the chemical constituents analyzed by gas chromatography (GC) and GC/mass spectrometry. The essential oil content was $0.67 \%(\mathrm{v} / \mathrm{w})$. Sixteen compounds were identified in the oil and included: neryl acetate $(51.4 \%)$, $\alpha$-pinene $(17.2 \%)$, $\alpha$ - eudesmol $(6.9 \%)$, geranyl propionate $(3.8 \%)$,, -eudesmol $(1.8 \%)$, limonene $(1.7 \%)$, and camphene $(1.6 \%)$. While the aroma of the curry plant is similar to that of a mild curry powder, the volatile chemical profile of the curry plant does not resemble that reported for commercial curry mixtures.

The curry plant (Helichrysum italicum or H. angustifolium) (Tucker, 1986), native to the Mediterranean region, is a perennial ornamental plant with yellow flower bracts and a distinct curry-like odor. Also called whiteleaf everlasting (Liberty Hyde Bailey Hortorium, 1976), the plant is closely related to the large group of everlasting [H. orientale (L.) Gaertn. and Hottentot tea, H. serpyllifolium Less.) and grown horticulturally in herb and rock gardens due to its unique aromatic qualities and attractive appearance. The plant, however, is not used for culinary purposes and is not included in the "generally regarded as safe" (GRAS) listing (FDA, 1974). While the plant's popularity is due, in part, to the presence of volatile essential oils that are primarily responsible for the plant's odor, the actual chemical constituents that comprise the essential oil "remain poorly understood.

Much of the early analysis on the essential oil of H. italicum was conducted in the early 1900 s, before the use of sophisticated analytical techniques; the major constituent was found to include neryl acetate, with nerol and $\alpha$-pinene reported as additional constituents (Guenther, 1952). Guenther (1952) reported that wild-growing $H$. italicum had been collected in the Dalmatian region of southern Europe and that the leaves plus flowering

Received for publication 7 Mar. 1990. Journal Paper no. 12,416, Purdue Univ. Agr. Expt. Sta., West Lafayette, IN 47907. This work was supported in part by a grant from the Purdue Univ. Agr. Expt. Sta. (Specialty Crops Grant no. 0141165-0000-65178). We express our appreciation to Peter Bwchard for providing the curry plants used in this study, the assistance of Renee Murray for botanical verification, and Karl Wood, Dept. of Chemistry and Mass Spectrometry Laboratory, who assisted us in the GC/MS analysis. The cost of publishing this paper was defrayed in part by the payment of page charges. Under postal regulations, thispapertherefore must be hereby marked advertisement solely to indicate this fact.

'To whom reprint requests should be addressed. tops had been distilled for the extraction of -essential oils. This oil was known as helichrysum oil in Dalmatia and was marketed for it's high concentration of neryl acetate that was used as raw material in the isolation of nerol (Guenther, 1952). The essential oil is also used in the fragrance industry (Peyron et al., 1979). Helichrysum oil was not, however, included in a recent compilation of world-wide essential oils of commerce (Lawrence, 1985). Essential oils from other species of Helichrysum have also been obtained and processed with $H$. italicum for the commercial product, and some of the essential oil constituents of helichrysums from various geographical regions have now been reported (Peyron et al., 1979; Weyerstahl et al., 1986). The aroma of the essential oil has been described as reminiscent of rose and chamomile (Guenther, 1952). Manitto et al. (1972) reported that two minor B-diketones, including 2,4-dimethylheptane-3,5-dione, were responsible for an unpleasant odor of the stems of $H$. italicum. Whether plants of

Table 1. Essential oil composition of the curry plant.

\begin{tabular}{lcc}
\hline \hline Essential oil & Percent of total oil $\pm \mathrm{SD}^{z}$ & $\begin{array}{c}\text { Relative retention time } \\
\text { (min) }\end{array}$ \\
\hline$\alpha$-Pinene & $17.2 \pm 8.2$ & 5.39 \\
Camphene & $1.6 \pm 0.5$ & 5.75 \\
$\beta$-Pinene & $0.2 \pm 0.1$ & 6.56 \\
Myrcene & $0.04 \pm 0.02$ & 7.43 \\
Limonene & $1.7 \pm 0.4$ & 8.30 \\
Terpinolene & $0.4 \pm 0.04$ & 10.54 \\
Linalool & $0.3 \pm 0.04$ & 11.18 \\
Borneol & $0.05 \pm 0.01$ & 14.75 \\
$\alpha$-Terpineol & $1.4 \pm 0.19$ & 15.68 \\
Nerol & $0.24 \pm 0.15$ & 17.15 \\
Neryl acetate & $51.4 \pm 7.19$ & 23.57 \\
Geranyl propionate & $3.8 \pm 0.4$ & 26.69 \\
1H-benzocycloheptene,2,4a,5,6,7,8- & & \\
$\quad$ hexahydro-3,5,5,9-tetramethyl-,(R) & $1.5 \pm 0.9$ & 28.02 \\
Guaiol (isomer) & $1.5 \pm 0.9$ & 33.49 \\
$\beta$-Eudesmol & $1.8 \pm 0.9$ & 34.18 \\
$\alpha$-Eudesmol & $6.9 \pm 2.6$ & $35.14 ; 36.24^{z}$ \\
Guaiol (isomer) & $0.6 \pm 0.06$ & 40.16 \\
\hline
\end{tabular}

${ }^{2} \alpha$-Eudesmol eluted as two peaks.
H. italicum grown for essential oil in Europe are of the same chemotype as the curry plant that is used horticulturally in this country is unknown.

While the aroma of the curry plant is reminiscent of the aroma of a mild curry powder, neryl acetate has a rose-like odor, rather than a spicy curry odor. Curry is a powdered mixture of spices, composed of two to 20 spices, with the number and relative proportions of each dependent upon the desired flavor and aroma. The most common ingredients include: cumin, ginger, coriander, cinnamon, tumeric, red pepper, fenugreek, allspice, black pepper, cardamom, cloves, mustard, and nutmeg (Heath, 1981). The objective of this study was to characterize the essential oils responsible for the characteristic odor of the curry plant.

Four curry seedlings were obtained from Companion Plants (Athens, Ohio) and transplanted into individual 7.2-liter standard plastic pots. The soil mix was 1 sterilized topsoil $: 1$ peat moss $: 1$ perlite (by volume) supplemented daily with a fertilizer solution containing $200 \mathrm{ppm} \mathrm{N}, 200 \mathrm{ppm} \mathrm{K}$, and adjusted to $\mathrm{pH} 6.0$ with phosphoric acid. Plants were grown under greenhouse conditions (day maximum, 27C; night minimum, 18C) from January through April. Supplemental lighting was provided by very high-output fluorescent tubes that emitted between 110 and $140 \mu \mathrm{mol} \cdot \mathrm{s}^{-1} \cdot \mathrm{m}^{-2}$, as measured by a LICOR LI-1776 quantum meter and LI-190SB sensor (LI-COR, Lincoln, Neb.) at the plant leaf level. Three plants were harvested individually at full bloom for essential oil analysis. Flowering tops and leaves were manually removed from the plants and ovendried at 30C as described by Charles and Simon (1990b). A fourth plant was dried and deposited in the Herbarium of the Field $\mathrm{Mu}$ seum of Natural History, Chicago.

Distillation and analysis. Dried leaves (75 g) were placed into 2-liter round-bottomed boiling flasks with 1 liter of distilled-deionized water, and the essential oil was extracted by hydrodistillation ( $1 \mathrm{~h} 15$ rein) via a modified Clevenger trap (Charles and Si- 
men, 1990b; ASTA, 1968). The essential oil content was determined on a volume : dryweight basis (percent $\mathrm{v} / \mathrm{w}$ ). The values for essential oil content and composition were based on the extraction of essential oil from each of the three plants analyzed separately, and the relative peak area for individual constituents was averaged. Identification of essential oil constituents was based on retention time and coinjection with authentic compounds. The relative percentages were determined using a Varian 3700 gas chromatography (Varian, Walnut Creek, Calif.) equipped with a flame ionization detector (FID) and an electronic 4270 integrator (Charles and Simon, 1990a; Simon and Quinn, 1988). Pure compounds ( $\alpha$-pinene, camphene, ß-pinene, myrcene, limonene, linalool, borneol, nerol, neryl acetate, and $\alpha-1$ terpineol) and essential oil constituents were also analyzed by a Finnigan 4000 gas chromatograph/mass spectrometer (GC/MS; San Jose, Calif.) using electron impact and hooked on-line to a Data General Nova/4 data processing system for compound identification as described by Simon and Quinn (1988).

Sixteen compounds (including all compounds $\geq 0.04 \%$ ) were identified in the essential oil, thus accounting for the constituents that play a significant role in the aroma of the plant (Table 1). Contrary to one report on Yugoslavian-grown $H$. italicum, which contained only $6.1 \%$. neryl acetate and $>35 \%$ sesquiterpenes (Weyerstahl et al., 1986), we found neryl acetate to be the major constituent $(51.4 \%)$, followed by $\alpha$-pinene $(17.2 \%)$ with all others present in minor concentrations $(<5 \%)$. While our results regarding neryl acetate are in agreement with earlier studies reported by Guenther (1952), our report also quantifies many additional constituents in the essential oil, which together account for the overall aroma of the plant. Zola and Levanda
(1976) reported that the essential oil of $H$. angustifolium was rich in nerol $(36.5 \%$ to $49.6 \%$ ) and neryl acetate (26.5\% to $35.4 \%$ ), in contrast to this study, where nerol was present in low concentration $(0.24 \%)$. While the odor of the curry plant is distinctly similar to a mild curry powder, the individual chemical constituents in the essential oil do not resemble those reported for commercial curry mixtures (Heath, 1981). Head-space analysis (Chialva et al., 1981) may have captured, if present, additional very light volatile and aromatic molecules that could have been lost during hydrodistillation. However, it appears unlikely that the presence of such compounds could significantly contribute such a curry-like aroma. The major volatile essential oils from plants found in curry mixtures are comprised of chemical constituents that are recovered by steam and hydrodistillation. While there may be nonvolatile essential oils present in the curry plant, most of the plants overall fragrance can best be attributed to the combination or blend of distinct aromas from each of the reported 16 constituents.

\section{Literature Cited}

American Spice Trade Association. 1968. Official analyticalmethods of the American Spice Trade Association. ASTA, Englewood Cliffs, N.J.

Charles, D.J. and J.E. Simon. 1990a. Essential oil constituents of Ocimum micranthum Willd. J. Agr. \& Food Chem. 38:120-122.

Charles, D.J. and J.E. Simon. 1990b. Comparison of extraction methods for the rapid determinationofessentialoilcontentand composition of basil (Ocimum spp.) J. Amer. Soc. Hort. Sci. $115: 458-462$

Chialva, F., G. Gabri, P.A.P. Liddle, and F. Ulian. 1982. Qualitative evaluation of aromatic herbs by direct head space $(\mathrm{GC})^{2}$ analysis. Applications of the method and comparison with the traditional analysis of essential oils, p. 183-195.
In: N. Margaris, A. Koedam, and D. Vokou (eds.). Aromatic plants-Basic and applied aspect. Martinus Nijhoff, Netherlands.

Food and Drug Administration, Department of Health, Education, and Welfare. 1974. Code of federal regulations. Title 21, CFR 180.73. Office of the Federal Register, U.S. Government Printing Office, Wash., D.C.

Guenther, E. 1952. The essential oils. reprinted 1985. Kleger Publishing Co., Malabar, Fla. 5:467-472.

Heath, H.B. 1981. Source book of flavors. AVI, Westport, Conn.

Lawrence, B.M. 1985. A review of the world production of essential oils (1984). Perfumer \& Flavorist 10:1, 3-10, 12-16.

Liberty Hyde Bailey Hortorium. 1976. Hortus Third. MacMillan, New York

Manitto, P., D. Manti, and E. Colombo. 1972. Composite: Two new B-diketones from Helichrysum italicum. Photochemistry 11:21122114.

Peyron, L., J. Acchiardi, B. Bruni, J.C. Rossi, and R. Granger. 1979. Composition of Helichrysum essential oils, p. 421-424. In: VII Intl. Congr. Essential Oil, 7-11 Oct. 1977, Kyoto, Japan.

Simon, J.E. and J. Quinn. 1988. Characterization of essential oil of parsley. J. Agr. \& Food Chem. $36: 467-472$

Tucker, A.O. 1986. Botanical nomenclature of culinary herbs and potherbs, p. 67-68. In: L.E. Craker and J.E. Simon (eds.). Herbs, spices and medicinal plants: Recent advances in botany, horticulture, and pharmacology. vol. 1. Oryx Press, Phoenix, Ariz.

Weyerstahl, P., H. Marschall-Weyerstahl, M. Weirauch, N. Meier, E. Manteuffel, J. Leimner, and S. Scholz. 1986. Isolation and synthesis of compounds from the essential oil of Helichrysum italicum, p. 177-195. In: E.J. Brunke (cd.). Progress in essential oil research. Walter de Gruyter, Berlin

Zola, A. and J.P. Levanda. 1976. Quelques huiles essentielles en provenance de la case. Rivista Ital. Essenze, Profumi, Piante Off., Aromi, Saponi Cosmetici, Aerosol 57:467-472. 